\title{
O uso do Arduino e a criação de objetos educacionais em tempos e espaços desarticulados
}

\author{
Luis Henrique Monteiro de Castro \\ Escola Técnica Estadual Ferreira Viana \\ Fundação de Apoio à Escola Técnica \\ Rio de Janeiro RJ, Brasil \\ luishmcastro@gmail.com
}

\author{
Prof $^{a} D^{a}$. Rosemary dos Santos \\ Universidade do Estado do Rio de Janeiro \\ Rio de Janeiro RJ, Brasil \\ rose.brisaerc@gmail.com
}

\begin{abstract}
Resumo - Esse artigo traz uma proposta de uso do Arduino como recurso educacional para a criação de atividades desenvolvidas de forma transdisciplinar, de baixo custo e de qualidade para o uso em substituição ou complementação aos laboratórios tradicionais de Ciências, quando presentes nas escolas. A intenção primeira deste trabalho consistiu em mapear a experiência pedagógica da aplicação do objeto educacional Estação Meteorológica de baixo custo com alunos de uma escola na zona norte do município do Rio de Janeiro. Como achado da pesquisa constatamos que a proposta de montagem do experimento de forma colaborativa oportunizou que os alunos tivessem a oportunidade de observar, de analisar, de interpretar e de produzir conhecimentos e soluções para situações do cotidiano e de natureza acadêmica.
\end{abstract}

Palavras-chave - Educação, Objetos Educacionais, Arduino, Processing

\section{INTRODUCÃO}

Para favorecer o aprendizado dos conteúdos apresentados no ensino de ciências as aulas deveriam ser amparadas em práticas pedagógicas que favoreçam uma associação entre o ensino teórico ministrado em sala de aula e a prática desenvolvida nos laboratórios didáticos. Uma vez que as atividades experimentais deveriam ser o momento pedagógico de comprovação e de sedimentação dos modelos apresentados aos alunos nas atividades teóricas, fazendo, também, com que eles passem a ver, através da utilização de experimentos, as ciências como algo presente em seu cotidiano, promovendo o interesse de investigar e tirar conclusões, deixando, assim, de ser uma área do conhecimento cheia de leis, conceitos e exercícios repetitivos, minimizando as dificuldades de aprendizado e propiciando o aprendizado de maneira significativa e consistente. A oportunidade de conhecer, de manipular e de controlar os experimentos, acaba por facilitar o aprendizado dos conceitos e por despertar o interesse do aluno nas ciências.

Essa visão do laboratório didático é proposta pelos PCN (Parâmetros Curriculares Nacionais), desenvolvidos pelo

\footnotetext{
${ }^{1}$ O Observatório do PNE é uma plataforma online que tem como objetivo monitorar os indicadores referentes a cada uma das 20 metas do Plano Nacional de Educação (PNE) e de suas respectivas estratégias, e oferecer análises sobre as políticas públicas educacionais já existentes e que serão implementadas ao longo dos dez anos de vigência do Plano.

${ }^{2}$ Laboratório de ciências está presente em 8,19\% das Escolas de Ensino

Fundamental e em 44,40\% das Escolas de Ensino Médio.
}

Ministério da Educação. Estes parâmetros preconizam a utilização de objetos educacionais que simulem situações problema ou tentativas de solução, e não apenas uma proposta realizada com o intuito de verificar através de atividades experimentais apenas as leis e teorias previamente determinadas, onde muitas vezes o aluno não possui tempo de entender ou de relacionar o significado das atividades:

É indispensável que a experimentação esteja sempre presente ao longo
de todo o processo de desenvolvimento das competências em Física,
privilegiando-se o fazer, manusear, operar, agir, em diferentes formas
e níveis. É dessa forma que se pode garantir a construção do
conhecimento pelo próprio aluno, desenvolvendo sua curiosidade e o
hábito de sempre indagar, evitando a aquisição do conhecimento
científico como uma verdade estabelecida e inquestionável. [1]

No entanto, a realidade das escolas públicas brasileiras está bem distante deste ideal. Segundo o último levantamento divulgado pelo Observatório ${ }^{1}$ do PNE (Plano Nacional de Educação) [2], em 2014 somente 8,4\%² das unidades escolares de Ensino Básico da Rede Pública de Ensino contavam com um laboratório de Ciências em suas instalações.

Ademais, laboratórios modernos, com equipamentos sofisticados, nem sempre garantem bons resultados, pois estão, muitas das vezes, distantes da vivência dos alunos:

\footnotetext{
As abordagens mais tradicionais precisariam, portanto, ser revistas, evitando-se "experiências" que se reduzem à execução de uma lista de procedimentos previamente fixados, cujo sentido nem sempre fica claro para o aluno. É tão possível trabalhar com materiais de baixo custo, tais como pedaços de fio, pequenas lâmpadas e pilhas, quanto com kits mais sofisticados, que incluem multímetros ou osciloscópios. A questão a ser preservada, menos do que os materiais disponíveis, é, novamente, que competências estarão sendo promovidas com as atividades desenvolvidas [3].
}

Experimentos de baixo custo não são, exatamente, uma novidade ${ }^{3}$. Alguns já têm sido utilizados, e não apenas pela razão financeira, que os caracteriza, mas pela facilidade de montagem e exemplificação de fenômenos físicos em ambientes desprovidos de um laboratório didático. No

\footnotetext{
3 Pelo menos desde a década de 90 do século $\mathrm{XX}$, são propostos experimentos de baixo custo em substituição aos precários ou inexistentes laboratórios de Física no Brasil. Vide Instrumentação para o Ensino de Física em Níveis de $1^{\circ}$ e $2^{\circ}$ Graus In: Revista Brasileira de Estudos Pedagógicos, 1993, p.713-738.
} 
entanto, muitos desses experimentos limitam-se a aspectos qualitativos, sendo incapazes de realizar medições com a precisão adequada.

Neste sentido, o uso de microcontroladores eletrônicos torna-se uma opção interessante na criação de dispositivos de baixo custo, pois possuem capacidade de medições com precisão adequada e com grande versatilidade de aplicações. Entre elas podemos citar o uso dos sensores de pressão, temperatura, campo magnético, altitude, umidade, posição, dentre outros. Porém a sua utilização possui uma forte resistência devido à necessidade de conhecimentos prévios de eletrônica básica e de programação, o que por si só restringe o público-alvo e seu viés de divulgação científica.

A utilização destes materiais, em geral, permite que se realizem experimentos físicos sem a necessidade de ambientes especiais para esse fim. Além disso, os fenômenos não ficam "ocultos" em equipamentos que o estudante não sabe exatamente como funcionam. Para Ribeiro, "aparelhos e montagens improvisadas, executadas com os recursos mais modestos laboratórios, deve ser considerada não como uma solução de emergência, mas ao contrário, como uma nova técnica desejável para desenvolver as capacidades construtivas e inventivas do estudante" [4].

Neste cenário, a plataforma Arduino [5] pode ser uma opção extremamente barata e de fácil programação, não exigindo de seu usuário um conhecimento rebuscado em eletrônica e programação. É uma plataforma de acesso livre, sendo seus códigos amplamente compartilhados pelos seus diversos usuários na internet. Estas características habilitam a plataforma Arduino como uma alternativa para a "produção de Recursos Educacionais Abertos (REA) destinados à pesquisa, à aprendizagem e à docência, a utilização e a resignificação de conteúdos educacionais de forma gratuita" [6].

\section{O ARDUINO E O PROCESSING}

O Arduino é uma plataforma de hardware e software open source 4 , programável, que permite interagir com o mundo a partir da aquisição de variáveis físicas através de sensores e interagir controlando luzes, motores e outros atuadores. O projeto Arduino é disponibilizado em diversas versões para atender aplicações bem diferenciadas.

Dentre todas as plataformas, as compatíveis com o Arduino UNO apresentam uma ótima relação custo $\mathrm{x}$ benefício, sendo assim se tornam um excelente ponto de partida para o usuário iniciante e para o uso em aplicações de baixa complexidade atrelada a um baixo custo. Baseado no microcontrolador ATmega328, produzido pela ATMEL, o Arduino UNO possui 14 pinos de entrada/saída digital, dos quais 6 pinos podem ser usados como saídas PWM (Pulse Width Modulation - Modulação por Largura de Pulso), 6 entradas analógicas, uma conexão USB, uma entrada de alimentação, uma conexão ICSP (In-Circuit Serial Programming - Conector Serial de Programação), um botão de reset, LEDs (Light Emitter Diode - Diodo Emissor

${ }^{4}$ Código aberto, ou open source, é um modelo de desenvolvimento que disponibiliza todas as informações a todos os usuários. Apesar dos projetos de Luz) indicativos do estado do pino 13 e da transmissão/recepção de dados através da interface serial (Pinos 0 e 1). A placa contém todos os componentes necessários para $\mathrm{o}$ adequado funcionamento do microcontrolador e sua interface com o computador.

Para a construção de objetos educacionais que permitam a obtenção de experimentos quantitativos a partir do Arduino é necessária a utilização de uma interface para a apresentação e análise de forma numérica e/ou gráfica dos dados adquiridos ao aluno. Comercialmente, há diversos softwares proprietários para esta finalidade, porém com elevado custo de licenciamento e muitas vezes se tornando inviável para as escolas públicas. Para manter a ideia do baixo custo, realizamos uma pesquisa dos softwares e livres que atendessem a este objetivo.

\section{Figura 1 - A placa Arduino UNO (lado conectores)}

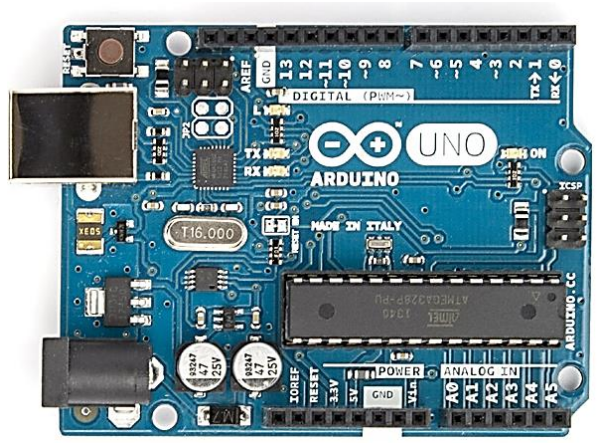

Fonte: Acervo do autor, 2016

Figura 2 - A placa Arduino UNO (lado placa)

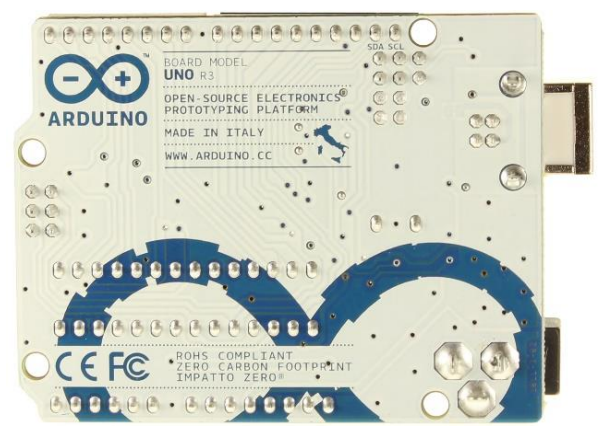

Fonte: Acervo do autor, 2016

Dentre as linguagens disponíveis, o Processing [7] foi a escolhida por apresentar grande similaridade com a linguagem utilizada para a programação do Arduino. Além de Ambientes de Desenvolvimento praticamente idênticos, a semelhança entre as duas linguagens perpassa a sua origem compartilhada, a linguagem wiring, o uso de funções e bibliotecas e a mesma estrutura de comandos, se distanciando apenas nas funções e bibliotecas específicas. Essa similaridade em muito facilita o uso do Arduino em conjunto com o Processing.

desenvolvidos sob esta ideologia possuírem boa qualidade, a gratuidade é o principal atrativo. 
Inicialmente desenvolvido para servir como um caderno de desenho e como um software para ensinar fundamentos de programação dentro de um contexto visual, o Processing evoluiu para uma ferramenta de desenvolvimento profissional, tornando-se uma alternativa às ferramentas de software proprietário com licenças restritivas e dispendiosas, sendo acessível para as escolas públicas e para os alunos individuais.

Em nosso contexto, o Processing foi o responsável pela interface com o Arduino, capaz de armazenar os dados em um arquivo no formato texto, para análise posterior, em softwares livres do tipo planilha eletrônica como o Libreoffice Calc ou de análise como o SCIDavis.

O canal utilizado para a comunicação entre o Arduino e o Processing é a conexão serial, em nossa proposta, estabelecida através de uma interface USB entre o computador e a placa Arduino.

\section{O OBJETO EDUCACIONAL - ESTAÇÃO METEOROLÓGICA COM O USO DO ARDUINO E DO PROCESSING}

A previsão do tempo está presente nos jornais, nos telejornais e na internet. É ela que permite, muitas vezes, as pessoas se prepararem para enfrentar as mudanças climáticas, levando, por exemplo, ao sair de casa, agasalhos e guarda-chuva, ou escolherem a melhor data para uma viagem ou para um evento.

Deste modo, é possível dizer que a meteorologia é um assunto que facilmente demonstra aos alunos as aplicações da Física no dia a dia, conforme salientam as orientações Educacionais Complementares aos Parâmetros Curriculares Nacionais: "a Física deve apresentar-se, portanto, como um conjunto de competências específicas que permitam perceber e lidar com os fenômenos naturais e tecnológicos, presentes tanto no cotidiano mais imediato quanto na compreensão do universo distante, a partir de princípios, leis e modelos por ela construídos" [8].

O termo meteorologia foi cunhado por Aristóteles, no século IV A.C, derivado de meteoro (partículas em suspensão) e logos (conhecimento). O termo foi empregado para nomear a ciência que estuda os fenômenos ocorridos na atmosfera terrestre ou mesmo de outros planetas.

No Brasil, o estudo da meteorologia se inicia em 1781, com a campanha de medições meteorológicas nas cidades do Rio de Janeiro e de São Paulo e a profissão de meteorologista foi regulamentada em 14 de outubro de 1980.

As estações meteorológicas monitoram, muitas em tempo real, nosso tempo e o nosso clima, possibilitando, através das medidas realizadas, o monitoramento do clima e a previsão do tempo. Para realizar essas atividades em sala de aula, um equipamento de baixo custo para a medição de algumas das variáveis atmosféricas pode ser desenvolvido com o uso do Arduino e do Processing, viabilizando o monitoramento da pressão atmosférica, da temperatura, da umidade relativa do ar e da luminosidade.

O estudo e a análise dos dados provenientes da medição desses parâmetros podem promover a integração entre algumas disciplinas como a química, física e biologia, da área de ciências da natureza; a geografia da área de ciências humanas e as disciplinas das áreas de linguagem.

Os estudos dos fenômenos atmosféricos estão intimamente relacionados à Física e à Química. Podemos citar, como exemplo destas relações, os processos termodinâmicos, a composição e a estrutura da atmosfera, a propagação da radiação eletromagnética e das ondas acústicas através da atmosfera, os processos físicos envolvidos na formação de nuvens e precipitação, a eletricidade atmosférica, as reações físico-químicas dos gases e partículas, a microfísica de gotas e cristais e a própria química da atmosfera. $\mathrm{O}$ conhecimento da atmosfera e das mudanças climáticas são apontados como um exemplo de aplicação da disciplina de química pela Base Nacional Curricular Comum:

As mudanças climáticas e o efeito estufa, o uso de feromônios como alternativa aos agrotóxicos no combate às pragas agrícolas, a necessidade de informações sobre a presença de transgênicos em rótulos de alimentos e os custos ambientais das minerações são apenas alguns exemplos de assuntos em que o conhecimento químico é vital para que o/a estudante possa posicionar-se e tomar decisões com consciência [9].

O processo biológico da fotossíntese e as reações químicas possibilitaram a evolução da atmosfera primordial formada por metano (CH4), amônia (NH3), dióxido de carbono $(\mathrm{CO} 2)$ e vapor de água $(\mathrm{H} 2 \mathrm{O})$ para a atmosfera que conhecemos hoje, onde predominam os gases nitrogênio $(\mathrm{N})$ e oxigênio $(\mathrm{O})$. Além dessa evolução, os processos biológicos interagem de forma constante com a atmosfera, como podemos exemplificar pelas florestas que mantém o equilíbrio ambiental (umidade do ar, temperatura, taxa de polinização etc.).

$\mathrm{Na}$ geografia, a conexão com as variáveis atmosféricas (temperatura, umidade relativa do ar, luminosidade etc.) se materializa nos estudos do clima, da vegetação, do relevo, da hidrografia e da climatologia presentes nos livros didáticos do Ensino Médio.

Nos livros didáticos de Física, as variáveis pressão e temperatura são normalmente apresentadas de forma generalizada e não específicas a atmosfera, enquanto os conceitos de pressão atmosférica, temperatura atmosférica, umidade relativa do ar e luminosidade estão presentes em fontes bibliográficas de geografia ou de meteorologia.

A pressão é definida como a razão entre a força aplicada em uma superfície e a área de aplicação dessa força. A pressão atmosférica é o peso exercido por uma coluna de ar, com secção reta de área unitária, que se encontra acima do observador, em um dado instante e local. Fisicamente, representa o peso que a atmosfera exerce por unidade de área, conforme define Varejão-Silva em seu livro Meteorologia e Climatologia [10]. A unidade padrão de pressão no Sistema Internacional (SI) é o Pascal (Pa) $(\mathrm{N} / \mathrm{m} 2)$. Meteorologistas tem usado tradicionalmente a unidade bar, mas a unidade Pascal vem sendo cada vez mais adotada. Por tradição histórica, ainda é utilizada a unidade milímetros de mercúrio $(\mathrm{mmHg})$. A referência para os valores de pressão atmosférica é o seu valor médio ao nível do mar: 1013,25 mbar, $101,325 \mathrm{kPa}, 1013,25 \mathrm{hPa}$ ou 760 $\mathrm{mmHg}$.

A temperatura é a medida da agitação das partículas que compõe um certo material. Se considerarmos as moléculas 
de um gás, quanto maior a sua temperatura mais energia cinética terão essas moléculas. Quando queremos medir a temperatura de um corpo, precisamos usar uma escala termométrica, isto é, uma maneira de correlacionar um conjunto de números às temperaturas. As três escalas termométricas mais comuns são grau Celsius $\left({ }^{\circ} \mathrm{C}\right)$, Fahrenheit (F) e Kelvin (K).

A noção comum subjetiva de temperatura não é, de forma alguma, confiável. Uma experiência familiar consiste em um dia muito frio tocar-se uma grade de metal que esteja ao ar livre e, em seguida, tocarse um objeto de madeira próximo. Tem-se a sensação de que a grade está mais fria, embora ambos os objetos estejam à mesma temperatura. $\mathrm{O}$ que se está testando quando se toca um objeto frio não é somente a sua temperatura, mas também a sua capacidade de transferir energia (na forma de calor) da mão (provavelmente quente). Nestes casos, a mão fornece uma medida subjetiva e incorreta da temperatura [11].

A umidade relativa do ar é definida como a razão entre o percentual (em número de moléculas) de água no ar pelo percentual que corresponde à saturação naquela temperatura do ambiente. Por exemplo, a $30^{\circ} \mathrm{C}$ pode existir no máximo $4 \%$ de moléculas de água no estado de vapor no ar; caso efetivamente exista apenas 3\%, então a umidade relativa do ar será 3 dividido por 4 , portanto, 0,75 ou $75 \%$. A autora Ercília Torres Steink nos esclarece a relação entre a umidade e a formação de chuvas em seu livro Climatologia Fácil:

Quando os instrumentos indicam umidade relativa de $100 \%$, isso quer dizer que o ar está totalmente saturado com vapor d'água e, àquela temperatura, ele não pode mais absorver vapor d'água. (...) quando a umidade relativa do ar está em torno de $100 \%$, ocorre a condensação, ou seja, a formação das nuvens, e, se as condições permitirem, a ocorrência de chuva. Isso não significa, porém, que a umidade relativa do ar deva ser de $100 \%$ para que chova — basta que seja $100 \%$ onde as nuvens estão se formando [12].

A medição da luminosidade permite determinar a iluminação solar, ou seja, o período que estamos sujeitos a irradiação solar. Com esta medição, também podemos observar, de maneira aproximada, o horário do nascer do sol e do pôr do sol (ocaso) em dias sem nebulosidade. Também podemos ter um indicador comparativo da nebulosidade do dia, pois dias menos nebulosos serão por consequência mais claros.

Sob o ponto de vista estritamente geométrico, o nascimento e o ocaso do Sol ocorrem quando o centro do disco solar aparentemente coincide com o plano do horizonte local. Na prática, porém, o nascimento e o ocaso do Sol são definidos como os instantes em que o bordo do disco solar parece tangenciar o plano do horizonte local, supostamente desobstruído. Nessas ocasiões, a verdadeira posição do centro do disco solar é 50' abaixo daquele plano. Isso advém do fato do raio daquele disco subentender um arco de $16^{\prime}$ e da refração atmosférica aumentar em cerca de 34' o ângulo de elevação do Sol, quando próximo à linha do horizonte [13].

Para o desenvolvimento da estação meteorológica com o uso do Arduino e Processing, são necessários, além do Arduino que realiza a aquisição dos dados e do Processing que implementa a interface gráfica, sensores que realizam a medição das variáveis meteorológicas. BMP-180 [14] módulo responsável pela medição de pressão atmosférica e temperatura; o módulo AOSONG AN2302 [15] para a medição de temperatura e umidade; um LDR comum para medição de luminosidade, um LED para demonstração de funcionamento da estação; uma matriz de contato para servir de base das conexões elétricas; e 3 resistores e alguns fios para completar todos os circuitos.

O esquema de ligações dos sensores e a ligação do LED indicador de funcionamento da estação ao Arduino são apresentadas a seguir:

Figura 3 - Esquema de ligações elétricas do Objeto Educacional com uso do software Fritzing [16]

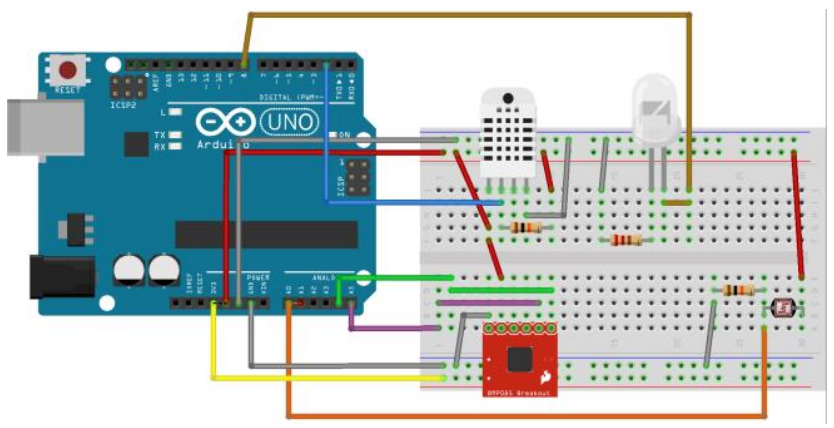

Fonte: Autoria própria, 2016.

\section{METODOLOGIA}

Todo o trabalho de montagem do objeto educacional foi realizado de forma colaborativa com alunos de uma escola na zona norte do município do Rio de Janeiro, em uma turma de doze alunos. Foram realizados dois encontros com duração de 100 minutos para apresentação aos alunos da proposta do projeto, do Arduino, do Processing e das características principais dos sensores a serem utilizados.

Figura 4 - Fotografia da montagem do Objeto Educacional

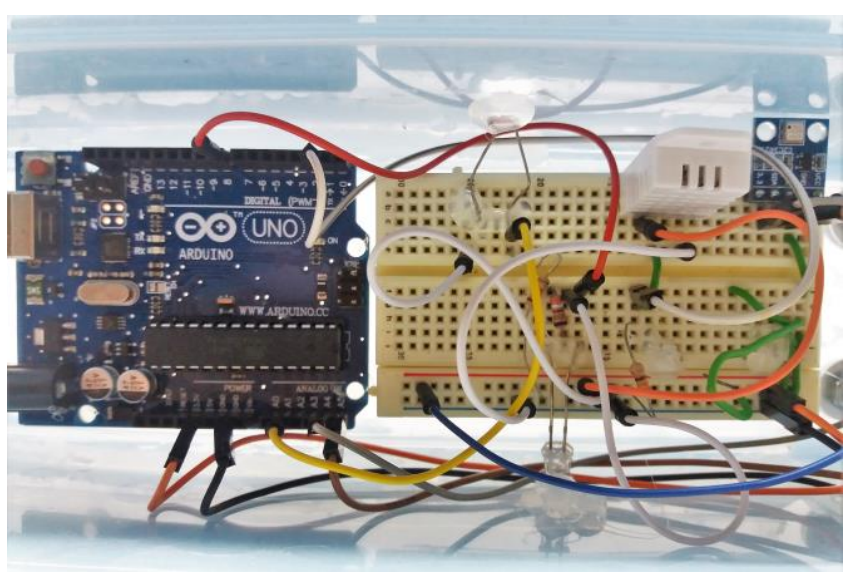

Fonte: Autoria própria, 2016.

Com mais dois encontros, foi realizada a montagem do experimento e seu invólucro constituído de um pote plástico para armazenamento de macarrão do tipo espaguete, sugerido e doado por um dos alunos. 
Figura 5 - Protótipo da estação meteorológica com o uso do Arduino e do Processing

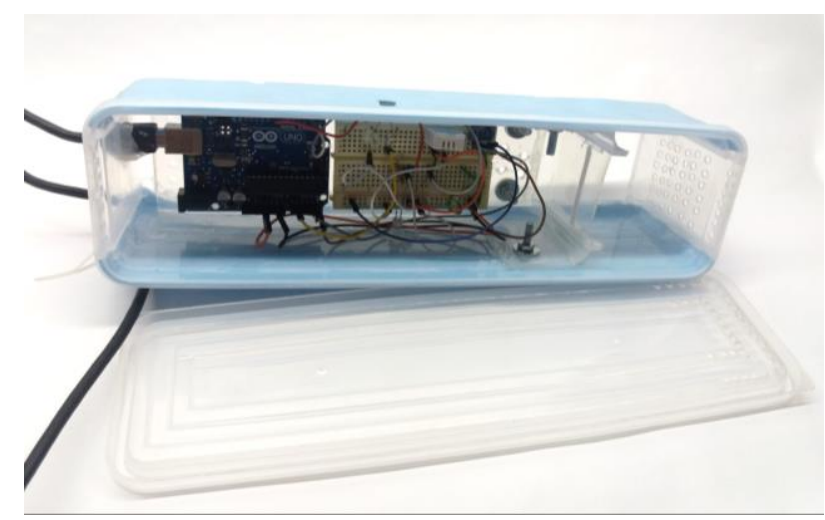

Fonte: Acervo do autor, 2016.

Outro encontro foi utilizado para a instalação do objeto educacional na janela da sala e ligação com o computador contendo o processing para o armazenamento dos dados em arquivo do tipo texto. Por sugestão de outro aluno foi inserida mais uma proteção ao experimento realizada com o corte de uma velha pasta plástica amarela.

Figura 6 - Alunos instalando o Objeto Educacional

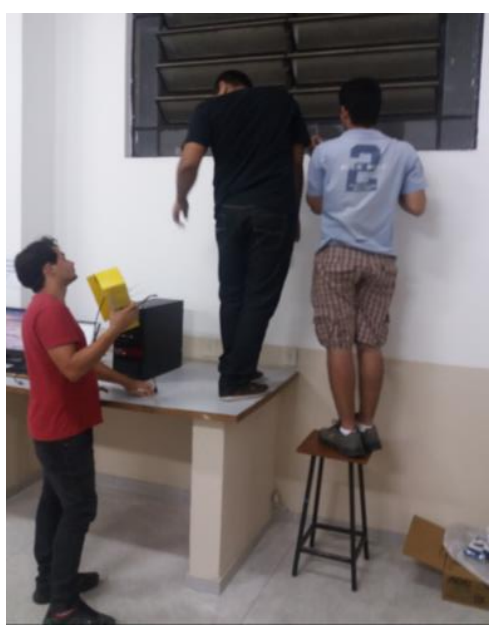

Fonte: Acervo do Autor, 2016.

Figura 7 - Computador coletando os dados

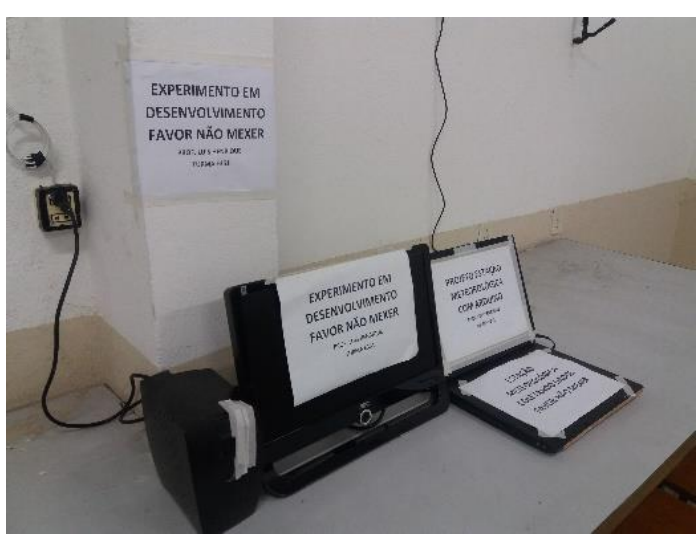

Fonte: Acervo do Autor, 2016.

Figura 8 - Detalhe da estação meteorológica instalada na janela da sala

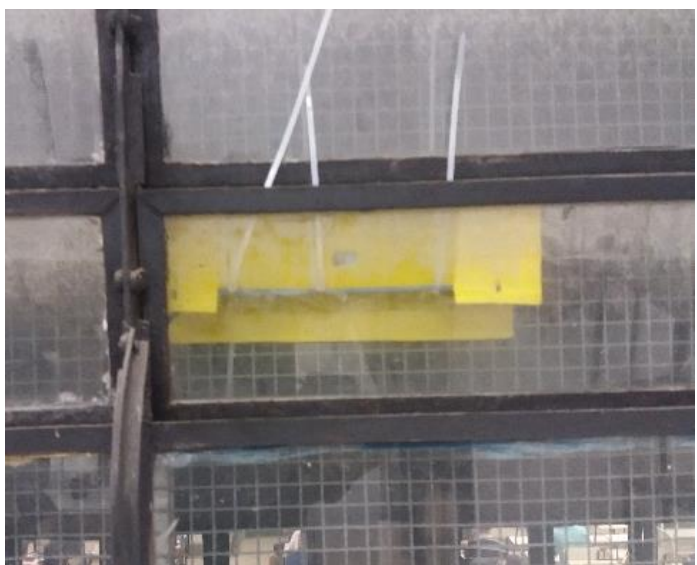

Fonte: Acervo do Autor, 2016.

Todo o material adquirido para a construção do experimento está relacionado na tabela 1 . Cabe ressaltar que o computador usado é de propriedade da ETEFV, assim como o cabo USB. O pote de plástico adaptado para o acondicionamento da estação, a pasta plástica usada para proteção contra chuvas e as braçadeiras plásticas para fixação do experimento à grade de proteção da janela foram trazidos pelos alunos.

Tabela 1 - Custo do Objeto Educacional

\begin{tabular}{|c|l|c|c|}
\hline Item & \multicolumn{1}{|c|}{ Descrição } & Quantidade & $\begin{array}{c}\text { Custo } \\
\mathrm{R} \$\end{array}$ \\
\hline 1 & Placa Arduino UNO & 01 & 35,00 \\
\hline 2 & $\begin{array}{l}\text { Protoboard } 480 \text { pontos } \\
- \text { Matriz de contatos } \\
\text { elétricos para } \\
\text { montagem de circuitos }\end{array}$ & 01 & 7,90 \\
\hline 3 & Resistor $10 \mathrm{k} \Omega \times 1 / 8 \mathrm{w}$ & 02 & 1,00 \\
\hline 4 & Resistor $220 \Omega \times 1 / 8 \mathrm{w}$ & 01 & 0,50 \\
\hline 5 & $\begin{array}{l}\text { LED de alto brilho } \\
\text { branco }\end{array}$ & 01 & 1,00 \\
\hline 6 & LDR 5mm & 01 & 2,50 \\
\hline
\end{tabular}




\begin{tabular}{|c|l|c|c|}
\hline 7 & $\begin{array}{l}\text { Sensor AOSONG } \\
\text { AM2302 }\end{array}$ & 01 & 18,00 \\
\hline 8 & BMP180 & 01 & 14,50 \\
\hline 9 & Jumpers para ligações & 25 & 5,00 \\
\hline \multicolumn{2}{|c|}{ Custo Total (referência: Ago. 2016) } & 84,40 \\
\hline
\end{tabular}

Fonte: Levantamento de custos no mercado de componentes eletrônicos RJ, 2016.

\section{RESUlTAdOS ALCANÇADOS}

Após o término da montagem e da instalação do experimento, foram gerados, pelo Processing, arquivos diários dados referentes as medições de temperatura, pressão atmosférica, umidade relativa do ar e luminosidade. Com base nestes arquivos e com o foco na validação do experimento, foi proposta aos alunos a comparação dos resultados obtidos pelo objeto com parâmetros medidos em estações meteorológicas próximas à escola com a elaboração de análise gráficas com o uso do software livre SCIDavis [17]. Para a pressão atmosférica, a temperatura e a umidade relativa do ar a comparação foi realizada com a estação do Sistema Alerta Rio, localizada no Campo de São Cristóvão [18]. Para luminosidade a comparação foi realizada com a estação do INMET localizada no Forte de Copacabana [19].

$\mathrm{Na}$ análise dos dados de temperatura feita com os alunos, observou-se a presença de um ciclo diário, com maiores temperatura durante o dia e menores temperaturas durante a noite. Eles puderam verificar, na prática, que existe uma correlação direta entre os picos de temperatura e os picos de luminosidade, os quais representam a insolação ou a energia absorvida das radiações solares.

Gráfico 1 - Comparação entre os dados de temperatura coletados

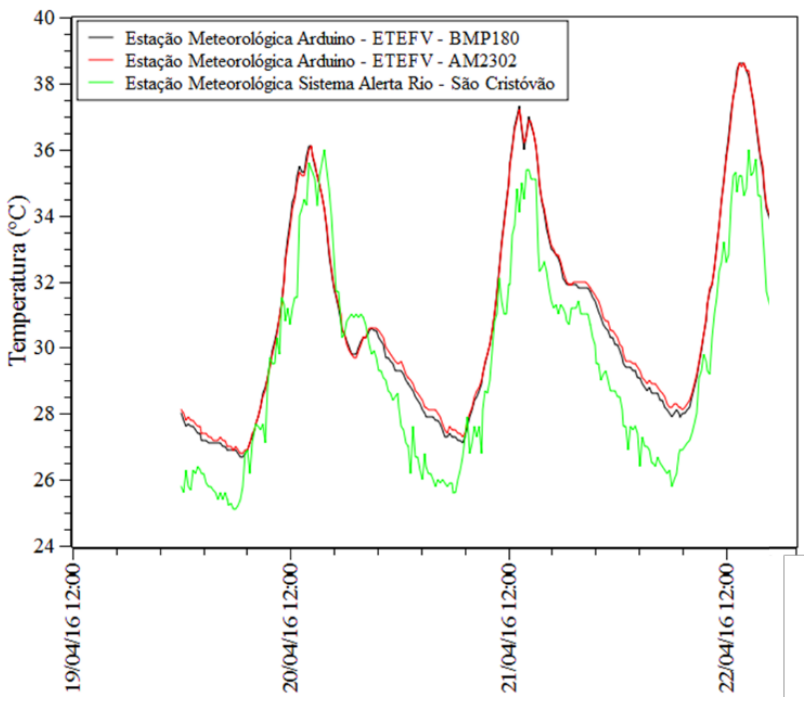

Fonte: Acervo do Autor, 2016.

Ainda analisando os dados individuais de temperatura, notou-se a proximidade das leituras dos sensores BMP180 e AM2302 e uma pequena disparidade com o sensor da Estação Meteorológica do Sistema Alerta Rio de São Cristóvão. Esta disparidade pode ser explicada pela diferença de localização dos sensores em cada estação. Ao apresentar aos alunos fotos da estação de São Cristóvão que se localiza no alto de um prédio, eles justificaram as variações devido aos aspectos de localização de cada uma das estações. "A estação de São Cristóvão está sujeita a repentinas variações de direção e velocidade dos ventos, enquanto a estação da ETEFV se encontra em um local abrigado e menos sujeita a essas variações”.

O gráfico de luminosidade obtido demonstra a alteração periódica da luminância entre o nascer do sol e o crepúsculo ou ocaso. Os alunos puderam observar há uma taxa de variação acentuada da luminosidade a partir do amanhecer, um pico próximo ao meio-dia e um decréscimo, também acentuado de luminosidade a partir deste ponto, até a escuridão total da noite.

Gráfico 2 - Gráfico dos dados referentes à luminosidade coletados pelo Objeto Educacional

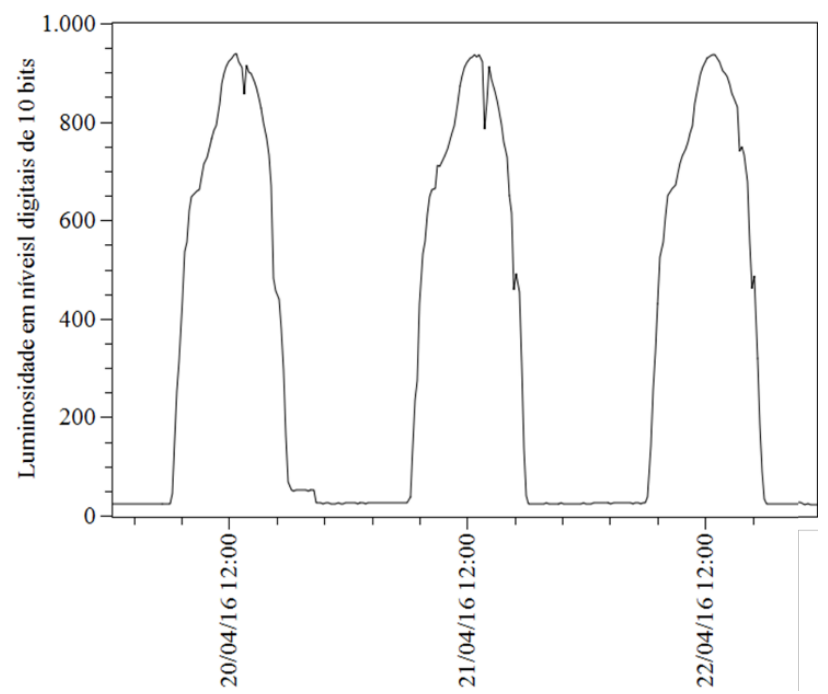

Fonte: Acervo do Autor, 2016.

Quando o período observacional se restringe a 24 horas o gráfico da luminosidade se apresenta de forma mais ampla e menos homogênea devido as variações de luminosidade, que deixam de ser pontuais e passam a se manifestar como deformações na tendência natural das taxas de incremento ou decremento da luminosidade no transcorrer do dia. Estas deformações são provocadas, principalmente, pela nebulosidade do dia ou pela passagem de nuvens. Neste gráfico também foram inseridas as posições efetivas do nascer do sol e do ocaso, que no dia 22/04/2016 ocorreram, respectivamente, às 6:09 e às 17:35.

Gráfico 3 - Gráfico dos dados referentes à luminosidade de um único dia coletados pelo Objeto Educacional 


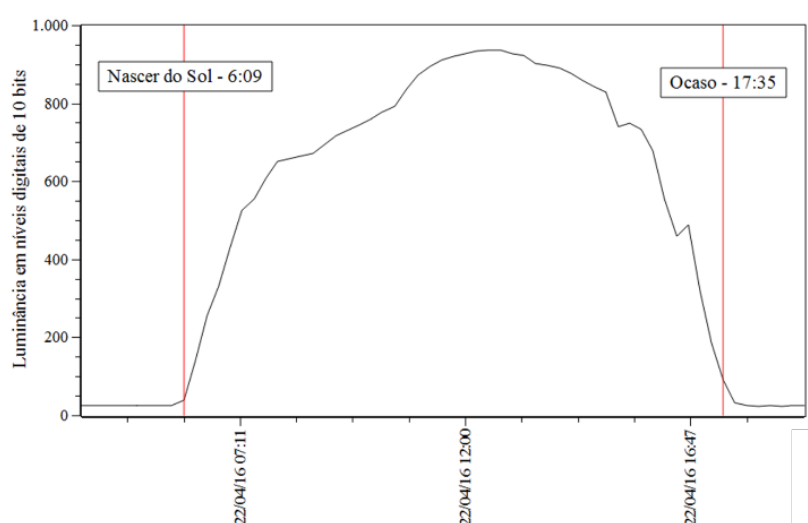

Fonte: Acervo do Autor, 2016.

Gráfico 4 - Gráfico dos dados referentes à luminosidade INMET - Forte de Copacabana

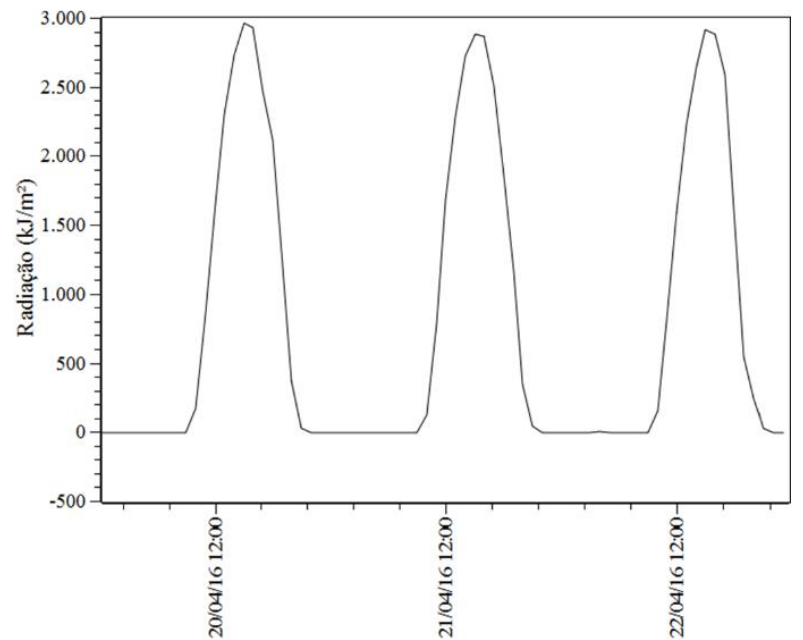

Fonte: Acervo do Autor, 2016.

Analisando o gráfico de umidade relativa do ar, foi possível perceber junto com os alunos a formação de ciclos diários com medições de umidade maiores à noite e menores durante o dia. A comparação dos dados da Estação Meteorológica do Sistema Alerta Rio de São Cristóvão, com os dados da estação com Arduino estão coerentes e dentro da variação máxima de amplitude. A disparidade encontrada nas medições pode ser explicada pela diferença de localização dos sensores de cada estação. A estação da ETEFV se encontra em um local abrigado, formando um gráfico mais comportado e com menor amplitude.

Gráfico 5 - Comparação entre os dados de umidade relativa do ar

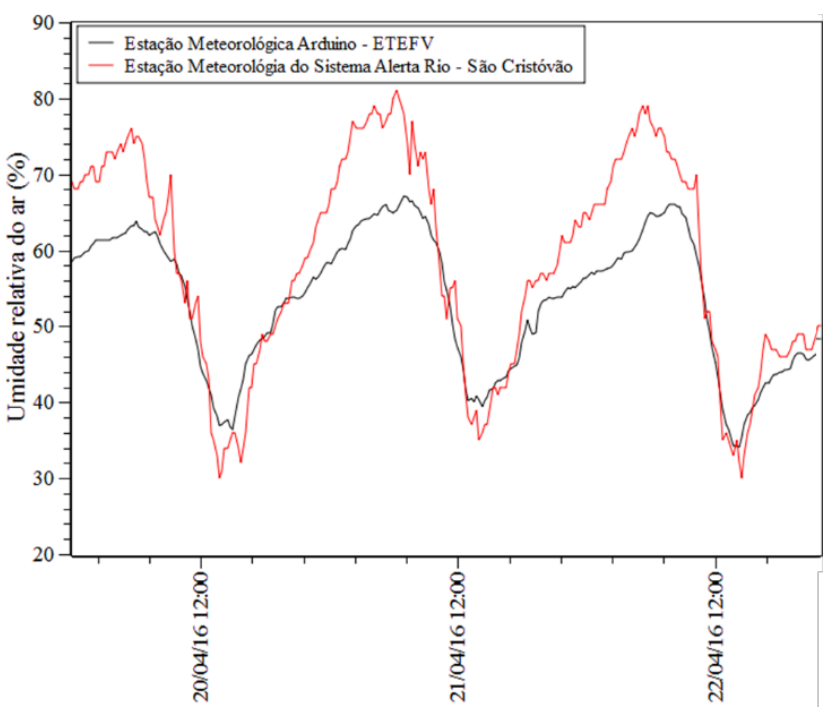

Fonte: Acervo do Autor, 2016.

Em comparação aos dados da Estação Meteorológica do Sistema Alerta Rio de São Cristóvão, os dados referentes à pressão atmosférica da estação com Arduino são semelhantes, porém com uma pequena discrepância em nível, oriunda da diferença de altitude entre as estações. Os alunos observaram que o gráfico da pressão atmosférica, diferentemente das outras grandezas, não se observa a formação de um único ciclo diário. A cada ciclo de 24 horas, é possível notar a formação de dois picos e dois vales, ou seja, há dois ciclos de variação da pressão por dia. Este fenômeno é conhecido como maré barométrica ou maré atmosférica.

Gráfico 6 - Comparação entre os dados de pressão atmosférica coletados

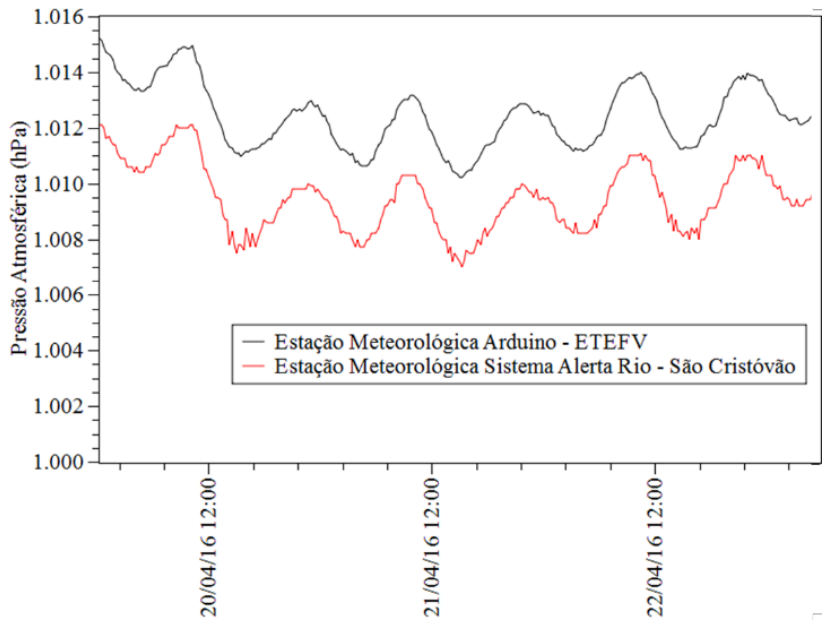

Fonte: Acervo do Autor, 2016.

\section{CONCLUSÃO}

A proposta de montagem do experimento de forma colaborativa oportunizou que os alunos tivessem a oportunidade de observar, de analisar, de interpretar e de 
produzir conhecimentos e soluções para situações do cotidiano e de natureza acadêmica.

Essas práticas foram fundamentais para despertar o interesse e a curiosidade do grupo, basilares para a investigação científica e o desenvolvimento tecnológico, mas também favorecem o incremento das habilidades e das competências necessárias para agir de forma objetiva frente a desafios dentro ou fora do contexto escolar.

Também é importante que outros professores e alunos se interessem e/ou interajam com este objeto educacional, podendo ser aprimorá-lo, adaptá-lo para outras realidades, para que ele possa ser o ponto de partida, um inspiração, para a criação de novos experimentos baseados no Arduino e no Processing relacionados aos tópicos curriculares do Ensino de Ciências, principalmente nas escolas que não possuam estrutura de laboratórios.

\section{REFERÊNCIAS}

[1] BRASIL. Ministério da Educação, Secretaria de Educação Média e Tecnológica. Orientações Educacionais Complementares aos Parâmetros Curriculares Nacionais ( $\mathrm{PCN}+)$ : ensino médio. Brasília: Ministério da Educação, 2013, p. 80.

[2] OBSERVATÓRIO DO PNE. Indicadores de acompanhamento das metas e estratégias Porcentagem de escolas da Educação Básica com acesso à água tratada, esgoto sanitário, energia elétrica, banda larga, biblioteca ou sala de leitura, quadra e laboratório de ciências. Brasília, 2014

[3] BRASIL. Ministério da Educação, Secretaria de Educação Média e Tecnológica. Orientações Educacionais Complementares aos Parâmetros Curriculares Nacionais $(\mathrm{PCN}+)$ : ensino médio. Brasília: Ministério da Educação, 2013, p. 81.

[4] RIBEIRO, J. C. O ensino experimental da Física no curso secundário. II Curso de aperfeiçoamento para professores de Física do ensino secundário. Atas do encontro. Pág.: 49-56. IBECC. MEC-ITA. São Paulo, 1955. p.54.

[5] ARDUINO. Disponível em: https://www.arduino.cc/. Acesso em: 3 de jul. 2019.

[6] SANTOS, E.; WEBER, A.; SANTOS, R. \& ROSSINI, T.(2012). Docência na cibercultura: possibilidades de usos de REA. In: Okada, A. (Ed.) (2012) Open Educational Resources and Social Networks: Co-Learning and Professional Development. London: Scholio Educational Research \& Publishing.
[7] PROCESSING. Disponível em: https://processing.org/. Acesso em: 3 de jul. 2016.

[8] BRASIL. Ministério da Educação, Secretaria de Educação Média e Tecnológica. Parâmetros Curriculares Nacionais: ensino médio. Brasília: Ministério da Educação, 2000, p. 2.

[9] BRASIL. Ministério da Educação, Secretaria de Educação Média e Tecnológica. Base Nacional Comum: Ministério da Educação, 2016, p. 146.

[10] VAREJÃO-SILVA, M.A. Meteorologia e Climatologia. Recife, 2006.

[11] HALLIDAY, D.; RESNICK, R. Fundamentos de física: gravitação, ondas e termodinâmica. 9. ed. Rio de Janeiro: LTC, 2003

[12] STEINKE, E.T. Climatologia Fácil. São Paulo: Oficina de Textos, 2012, p. 60.

[13] LIST, R. J. Smithsonian Meteorological Tables. Washington, USA: Smithsonian Institution, 1971.

[14] BOSCH. Digital Barometric Pressure Sensor BMP180. Disponível em: <https://www.boschsensortec.com/bst/products/all_products/bmp180>. Acesso em 20 abr. 2016.

[15] AOSONG, Electronics Co., Ltd. Temperature and humidity module - AM2302. Disponível em: < http://akizukidenshi.com/download/ds/aosong/AM 2302.pdf $>$. Acesso em 10 abr. 2016.

[16] FRITZING. Disponível em: <www.fritzing.org >. Acesso em: 25 jul. 2016.

[17] SCIDAVIS. Scientific Data Analysis and Visualization. Disponível em: http://scidavis.sourceforge.net/ Acesso em: 25 jul. 2016.

[18] RIO. Sistema Alerta Rio da Prefeiturea do Rio de janeiro. Dados meteorológicos da estação de São Cristóvão. Disponível em: http://www.sistemaalerta-rio.com.br/dados-meteorologicos /download/dados-meteorologicos/ Acesso em: 20 de jun. de 2016.

[19] BRASIL. Instituto Nacional de Meteorologia. Dados meteorológicos da estação Forte de Copacabana RJ. Disponível em: http://www.inmet.gov.br/sonabra/pg_dspDadosCo digo_sim.php?QTY1Mg==. Acesso em: 20 de jun. de 2016. 